\title{
THE COMPLETE AND CENTRALISED TREATMENT OF PARAPLEGIA ${ }^{1}$
}

\author{
By D. J. E. Cheshire, M.B., B.S., D.Phys. Med. \\ Spinal Injuries Centre, Austin Hospital, Heidelberg, Victoria, Australia
}

\section{INTRODUCTION}

IN November I966, the National Institute for Neurological Diseases held a Paraplegia Workshop to explore the problem of civilian paraplegia in all its aspects, suggest some means by which the problem could be handled, and to set in motion whatever steps might be necessary to implement the proposed solution. As opinion seemed to favour the establishment of comprehensive regional spinal injury centres, it was felt that there might be some value in presenting a report on such a centre in Victoria, Australia, which, for the past eight years, has been providing complete and centralised care for all the spinal cord injuries arising in a clearly defined area. One hundred per cent. of all patients with spinal cord trauma are admitted to the Centre. Patients are referred at the earliest possible moment. Currently, over 50 per cent. are being admitted within eight hours of the accident, and over 70 per cent. within 24 hours.

Australia is virtually the same size as the United States and consists of six sovereign states joined in a Federation. The relationship between the State and Federal Governments is very comparable to that of the United States. The fertile and industrialised state of Victoria lies in the south-east corner of Australia. It is a small state, occupying only 3 per cent. of the area of Australia but, with a population of $3 \frac{1}{4}$ million, contains 28 per cent. of the total population. Of the state's population, 2 million live in Metropolitan Melbourne, a sprawling conurbation extending over a 40-mile diameter.

Outside Metropolitan Melbourne there is only one city approaching 100,000 population, and three with approximately 50,000 populations. Beyond these cities the population is widely scattered. To the south of Victoria there is the island state of Tasmania with a population of just under half a million. To the immediate north, there is the Riverina district of New South Wales which is geographically and economically closer to Melbourne than to Sydney. The Spinal Injuries Centre for Victoria has evolved to provide total cover, not only for Victoria but also for Tasmania and the Riverina. Thus the Centre provides facilities for a total of some 4 million people, and this cover extends for a distance of between 300 and 400 miles in all directions of Melbourne, which is the pivot of the area.

In Australia, as in the United States, there is a system of private hospitals and public hospitals. The public hospitals, amongst which are included all the teaching hospitals, are dependent upon the State Government for the greater part of their finance, and hence are subservient to the State Hospitals and Charities Commission in matters of major policy. In general terms, the public hospitals operate on the principle of the means test and are available only to the less affluent sections of the community. However, there is an important exception to this principle, and if a patient is unable to obtain a particular specialised treatment in 1 Delivered to the Sixteenth Annual Spinal Cord Injury Conference of the Veterans' Administration of the United States of America, V. A. Hospital, Long Beach, California, 27th to 29th September 1967. 
a private hospital, he may, irrespective of his income, be admitted to a public hospital; this policy is applicable to the Spinal Injuries Centre. The Repatriation Department, the direct equivalent to the Veterans' Administration of the United States, has contracted out of the treatment of spinal cord injuries and buys this treatment from the civilian centre in each state; this makes good sense, because the number of Service-connected patients is insufficient to justify repatriation centres.

The Spinal Injuries Centre is part of the Austin Hospital, now a teaching hospital of the University of Melbourne. Originally a chronic hospital, the Austin had a disproportionate number of paraplegic patients. As the hospital evolved into an acute general hospital, so the Spinal Injuries Centre grew out of a dual need to care for existing paraplegic patients and an increasing awareness of the need for a proper centre. In 1957 Sir Ludwig Guttmann was invited by the State Government and the hospital to advise on the creation of a comprehensive centre, and his recommendations form the basis of the subsequent evolution.

\section{PHYSICAL ARRANGEMENT}

The Centre currently consists of 64 beds in three wards. The planning of these wards is, to some extent, contingent upon the fact that more than 80 per cent. of patients are male. This disparity has necessitated some compromises. The first ward to be considered is a I4-bed acute ward. Because more than 50 per cent. of all patients are admitted within eight hours of the accident, and more than 50 per cent. derive from automobile accidents, it will be apparent that in the planning of this ward it was necessary to cater not only for the nursing of a patient with acute spinal cord trauma but also for the problems of major resuscitation and the handling of serious multiple injuries. Therefore, the ward has evolved as both a ward in which the specialty of spinal nursing is practised, and an intensive care ward. Because the nursing of a patient with an acute spinal cord lesion is so complex and the numbers are so small, it was impractical to have a separate female acute ward, and the ward admits both male and female patients.

A patient is kept in the acute ward until he has achieved spinal stability and has been up in a wheelchair for about four hours in a day. At that stage the male patient graduates to a 28-bed rehabilitation ward. Although the main concept of the ward is rehabilitation, the patient remains in the same ward for such medical and nursing care as is necessary for any intercurrent illness during the rehabilitation phase, and for the necessary after-care following any urological investigation or operation.

The third ward is a 22-bed ward divided into two sections. One of the sections is for females and, regrettably, the small number of female patients means that patients who are undergoing rehabilitation are mixed with others who have been readmitted for the treatment of intercurrent conditions. The second section is for males, and is occupied by patients readmitted for intercurrent complications or for check-up.

In addition to the wards there are the usual rehabilitation facilities including physical therapy, remedial gymnastics, occupational therapy and manual arts therapy. There are as yet no facilities for hydrotherapy.

\section{TRANSPORTATION}

The procedure for admitting a patient varies according to whether the accident happens in the Melbourne-Metropolitan area or elsewhere, and at this 
point it is worth mentioning that although 50 per cent. of the population at risk lives in Melbourne, 70 per cent. of the spinal cord trauma sustained in automobile accidents occurs out in the countryside.

(a) Melbourne-Metropolitan Area. In the Melbourne-Metropolitan area the ambulance regulations rightly demand that a patient be taken from the scene of the accident to the nearest hospital. Medical education has achieved the adoption of a policy whereby a resident in a casualty department will diagnose spinal cord trauma on a history and a rapid clinical examination, and if he can satisfy himself that there is no medical reason to prevent the patient travelling to the Spinal Injuries Centre immediately, he will order the patient's onward movement by ambulance whilst he telephones the Centre to advise of the patient's coming. It is only in the event of other injuries which necessitate emergency treatment that the patient is retained in the first hospital, and then it is frequently no more than retention in the casualty department for resuscitation. Radiological examination js, in general, avoided at the first hospital, as, with staff who are unfamiliar with acute spinal trauma, the examination is potentially of more hazard than help, as well as wasting valuable time.

(b) Victorian Country Areas and Tasmania. The patient is taken from the scene of the accident to the nearest medical facility, where a diagnosis of spinal cord injury is made. The doctor telephones the centre, and, during the day, he is able to discuss the case and its management with the Director or the Assistant Director. At nights and weekends either the Director or the Assistant Director is on call, and it is usual practice for the hospital telephonist to divert the phone call from the doctor in the country to the Director in his home. The case is discussed over the telephone, the doctor in the country is advised on the treatment which should be provided, and the transportation of the patient to the Centre is arranged. The use of road or air ambulance is usually dependent upon the distance to be covered.

An air ambulance service is run by the State Health Department and is performed by three twin-engined Beachcraft Bonanza aircraft. These aircraft are continuously available and are capable of both night flying and instrument landing in bad weather. It is general policy that a doctor from the Centre travels in the air ambulance and takes over the patient's management at the earliest possible time. In this way respiratory complications and the risks of further damage to the spinal cord are minimised.

\section{ADMISSION OF A PATIENT WITH AN ACUTE SPINAL CORD INJURY}

When the Centre was being planned it was decided that there were two fundamental necessities in order to achieve the quickest and highest quality primary treatment. The first of these was that all unnecessary movement of the patient should be eliminated and, in particular, a plan should be devised whereby the shuttling of the patient from the casualty department to the X-ray department, to the ward and then possibly to the operating theatre should be avoided. The second necessity was that the optimum treatment of acute spinal cord trauma required the immediate participation of several specialists. 
The first criterion was met by the provision of an investigation and treatment area immediately adjacent to and connected with the acute ward. The patient is taken directly from the ambulance to this reception area, where he is met either by the Director or the Assistant Director. Whilst still on the ambulance stretcher a rapid but comprehensive clinical examination is performed, whereupon the patient is lifted safely under skilled supervision from the stretcher to a table. This table is actually an X-ray table, but is also used as an examination couch and, as will later be seen, a minor operating table. Clinical examination is completed and, in the same room with equipment which is a permanent installation, radiological examination is performed.

The room is maintained as a minor operating theatre, and using a system of pre-sterilised packs the necessary requisites for both emergency procedures such as intravenous infusion, tracheostomy and the insertion of an intercostal catheter, and for elective procedures, such as catheterisation of the bladder, the insertion of skull tongs and soft-tissue repairs, are constantly and immediately available.

It is therefore both the intention and the fact that in the great majority of cases the patient has one move from the ambulance stretcher to the X-ray table, and another from the X-ray table into his bed. It is only in a small number of cases that it is necessary to make an extra move and to take the patient to the operating theatre for a major surgical operation.

The other feature of the organisation is based on consultation between specialists in different fields. It is at this point necessary to state that the Director is a physiatrist, though inevitably, by his previous training in orthopaedic surgery and his experience over the years, he has acquired experience in the overall management of acute spinal cord trauma extending beyond physical medicine and rehabilitation. In parenthesis one would include the personal viewpoint that there is a great deal to be said for the director of a spinal injuries centre not to be personally involved in the active practice of any single branch of surgery.

The patient is received by the Director or the Assistant Director, and the resident medical officer. They are joined by the orthopaedic surgeon and the neurosurgeon on duty. Definitive treatment for the injuries to the spinal cord and vertebral column is planned in consultation, and should a major surgical or manipulative procedure be required, it is performed by the appropriate specialist. Other specialists may be called in at the same time. The resuscitationist is involved with nearly every patient, a thoracic surgeon or thoracic physician are frequently called in, and a general surgeon, neurologist and other specialists where appropriate.

The Director is in complete clinical charge. Theoretically it might be supposed that he would frequently have to arbitrate between the competing claims of, for instance, an orthopaedic surgeon and a neurosurgeon, but the practical beauty of this consultation scheme is that the longer it works the more do the members of the team learn a total, overall view of the management of acute spinal cord trauma, and the more they come to think on similar lines. In practice one finds that, with increasing experience the greatest problems arise not in the management of the spinal cord but in relation to associated injuries. It is perhaps in the combination of major associated injuries and an incomplete spinal cord lesion that the Director may have to be most firm in establishing the priorities of the different injuries. 


\section{REHABILITATION}

As the patient passes through the acute phase into the rehabilitation phase and towards discharge from hospital, his total programme is co-ordinated by the Director. It is the Director's responsibility that the orders of any surgeon or physician who has been consulted are carried out, and also to bring in from time to time any other specialists whose assistance may be required. As an example of the way in which the Director and his staff fit with the specialist units, one can do no better than to summarise the relationship with the urologist. Catheter drainage of the bladder, treatment of intercurrent infection, if any, and later, investigation of the urinary tract are carried out by the permanent staff of the Centre. In straightforward cases they direct the rehabilitation nurses to complete bladder training. However, in the event of difficulty, be it serious urinary infection, the discovery of ureteric reflux, or difficulty in bladder training, the urologist is consulted, and thereafter the management of the patient's urinary tract is one of the closest co-operation between the Director and his staff, on the one hand, and the urologist on the other.

At the same time the Director is responsible for the planning and coordination of the patient's physical and psychological rehabilitation. He is himself, in his specialty as a physiatrist, the person directly responsible for the programme of physical rehabilitation.

$\mathrm{He}$ is also responsible for bringing in the social worker at the earliest time and for ensuring that all necessary social assistance is given. One of the important problems which confronts a regional spinal injuries centre is to cater in the immediate post-accident phase for the requirements of relatives from the country. They must be brought to the city and accommodated near the hospital; in many instances temporary employment for wives must be found. Every assistance must be given with regard to unemployment benefits and pensions, and the patient must often be assisted towards the commencement of legal proceedings. Later the social worker together with the physical therapist and occupational therapist must visit the patient's home, and be sufficiently knowledgeable to make firm recommendations about the suitability or otherwise of the home and such modifications as may be required. Despite the distances involved these visits are vital and cannot be delegated to other agencies. At the same time the psychologist and occupational therapist are assessing the patient's educational standards and pre-accident employment, and studies are being carried out concerning his future employment. All these tasks are continuously under the overall sypervision of the Director, and weekly conferences are held to bring different opinions to bear and to formulate a co-ordinated policy.

The general population and employers of our country are not yet adequately conditioned to the employment of the disabled and particularly to the employment of the paralysed. At the present time there is no alternative to the running of a strong re-employment programme by those most directly concerned with the rehabilitation and welfare of paraplegics. In Victoria there is an active and expanding Paraplegic Association, modelled in many ways on the lines of the P.V.A. and, currently, employment is the responsibility of a joint sub-committee of the Spinal Injuries Centre and the Paraplegic Association which is chaired by the Assistant Director. 


\section{DISCHARGE FROM HOSPITAL}

On completion of treatment the patient is, whenever possible, discharged to his home. By then not only will the patient have achieved maximum rehabilitation but his family will have been educated, his home modified and his employment arranged. Thereafter his requirements are met by the Centre, the Paraplegic Association and a domiciliary nursing service.

The Paraplegic Association supplies any remaining social welfare needs, provides a social focus for paraplegics, particularly in the Melbourne-Metropolitan area, and provides the focus for all paraplegic sporting activities.

With patients in the Melbourne-Metropolitan area, the greatest assistance is given by the Royal District Nursing Service-a domiciliary nursing service of the highest quality. The most cordial relationship exists between the Royal District Nursing Service and the Spinal Injuries Centre, and the Centre is continuously running courses to familiarise nursing sisters with the techniques of spinal nursing. Particularly for tetraplegics it is usual to request the assistance of the District Nursing Service.

\section{PARAPLEGIC HOSTEL}

Experience in England suggested, and further experience in Melbourne has proved, that a regional spinal injuries centre is incomplete without a residential hostel for working paraplegics. In the Victorian context this need arises from two sources. Firstly, re-employment of paraplegics is relatively easy in Metropolitan Melbourne, but the further one goes out to the periphery the more difficult and even impossible this becomes particularly for those who have no great education or pre-accident skills. Secondly, Australia is a country with a high migrant intake, and a considerable number of paraplegics are young migrants without family or home. It was therefore essential to establish a residential hostel for working paraplegics in the Metropolitan area and with convenient access to industry.

\section{LONG-TERM CARE}

It is fundamental policy that all patients who have been through the Centre shall remain under the same care for the duration of their lives. This implies that the Centre shall conduct an out-patient clinic, and also that beds shall be available to provide an in-patient check-up at yearly intervals. Secondly, for the Centre to function effectively, it is necessary that beds be available not only for the treatment of the direct complications of spinal paralysis, such as decubitus ulcers and chronic renal disease, but also for the treatment of any significant illness that befalls a paraplegic. It must be firmly understood by all medical men and administrators that the only place for a paraplegic to be treated for any significant medical condition is a spinal injuries centre, because it is only by his being treated in a centre that he will avoid the development of one of the complications of spinal paralysis, such as decubitus ulcers, whilst under treatment for the illness which took him to another hospital.

\section{CONCLUSION}

At the Paraplegia Workshop to which previous reference has been made, Dr. David Barrie of the Liberty Mutual Insurance Company of Boston gave the following criteria for an adequate spinal cord injury programme 
I. Immediate skilled medical and physical care by physicians familiar with and qualified to treat spinal cord injuries.

2. Immediate hospitalisation in an institution equal in skill and experience to the physicians.

3. One person or agency with total responsibility for management of the case from its inception to its conclusion.

4. Early provision of financial assistance for medical and family living expenses.

5. Timely determination of vocational goals, and continuous efforts and direction towards obtaining such goals.

6. Permanent regular follow-up and examination.

7. Regional medical rehabilitation facilities specialising in spinal cord injuries, and affiliated preferably with a teaching hospital.

Australian experience would endorse every one of Dr. Barrie's criteria, and, moreover, Victoria demonstrates the complete realisation of the concept he annunciates. It is felt, however, that Dr. Barrie does not go far enough and that his criteria fall short in three significant areas. In the first place, as has been previously mentioned, it is essential that there should be, in continuation with and run by the spinal injuries centre, a residential hostel for working paraplegics. Secondly, it is felt that no spinal injuries centre can function adequately without the co-operation of a highly efficient domiciliary nursing service, working over as wide an area as possible-ideally, this should be the entire area served. Thirdly, no matter what standards of skill there may be in a spinal injuries centre, there will always be a certain number of patients who require permanent institutional care. These will either be high tetraplegics whose disability is so great that they cannot be nursed at home, or tetraplegics or older age-group paraplegics who, for some reason or other, cannot go home. It is only within the direct charge of a spinal injuries centre that these patients can be given adequate long-term nursing care, and it is also only in this environment that they can live as a group and maintain the necessary morale. A tetraplegic hostel of the type envisaged was opened two years ago by Sir Ludwig Guttmann at Stoke Mandeville, and one is being actively planned in Western Australia; regrettably one is not yet in sight in Victoria.

The planning of a complete regional spinal injuries centre must include not only the active treatment centre, but also a residential hostel for working paraplegics and long-term accommodation for those who must be permanently institutionalised.

In summary, the Spinal Injuries Centre of Victoria demonstrates a practical realisation of the policies expressed at the Workshop on paraplegia. It is not intended to suggest that the facilities in Victoria are perfect-far from it; there is a shortage of beds, a shortage of adequate trained medical, para-medical and nursing personnel, inadequacies in rehabilitation facilities, insufficient employment opportunity for tetraplegics, and there are no facilities for the long-term institutional care of tetraplegics. However, the principles are established, the framework is laid down and, probably most important, the concepts of earliest admission and total care are accepted by both the State Government and the medical profession.

\section{REFERENCES}

Austin, S. M. (I96I). The Spinal Cord, p. I7. Springfield: Thomas.

Damanski, N. (1965). Int. F. Paraplegia, 2, I7I.

Guttmann, L. (I963). Spinal Injuries Symposium, Roy. Coll. Surgeons, Edinburgh, Ed. P. Harris, pp. 80-92. 


\section{SPINAL INJURIES CENTRE FOR VICTORIA}

Some Statistics For the Seven Years, IST July I959 to 30Th JUNE I 966

\section{Admissions}

A. New Admissions

I. Spinal Cord Trauma .

(a) Admitted within I5 days of injury . . $\quad 325$

(b) Admitted between 15 days and 6 weeks . 15

(c) Admitted more than 6 weeks after injury . 50

2. Non-traumatic Spinal Paralysis . . . . . . . . 88

B. REAdmissions

789

Further Analysis of 325 Patients with Acute Spinal Cord Trauma, Admitted within I5 Days of Injury

\begin{tabular}{|c|c|c|c|}
\hline Males, & $(84 \%)$ & Females, & $55(16 \%)$ \\
\hline Age & $\begin{array}{l}\text { No. of } \\
\text { Patients }\end{array}$ & Age & $\begin{array}{l}\text { No. of } \\
\text { Patients }\end{array}$ \\
\hline (years) & & (years) & \\
\hline $0-10$ & 4 & $46-50$ & I8 \\
\hline II - I 5 & IO & $5 \mathrm{I}-55$ & I 8 \\
\hline $16-20$ & 78 & $56-60$ & 7 \\
\hline $21-25$ & 52 & $6 I-65$ & 7 \\
\hline $26-30$ & 36 & $66-70$ & 9 \\
\hline $3 I-35$ & 25 & $71-75$ & 4 \\
\hline $36-40$ & $3 I$ & $76-80$ & 3 \\
\hline $4 I-45$ & 22 & $80+$ & I \\
\hline
\end{tabular}

Time from Accident to Admission to Spinal Injuries Centre

\begin{tabular}{|c|c|c|}
\hline Time & $\begin{array}{c}\text { Melbourne } \\
325 \text { Patients in } 7 \text { Years }\end{array}$ & $\begin{array}{l}\text { Stoke Mandeville } \\
396 \text { Patients in } 6 \text { Years }\end{array}$ \\
\hline Less than 4 hours & $84(24 \%)$ & \\
\hline 4-8 hours & 75 ک $232(68 \%)$ & I94 (49\%) \\
\hline $\begin{array}{l}8-12 \text { hours } \\
\text { I2-24 hours }\end{array}$ & $j^{232(00 / 0)}$ & $24+4870)$ \\
\hline $24-48$ hours & 36 & 40 \\
\hline $2-7$ days & 44 & 95 \\
\hline 7 -I 5 days & I3 & 67 \\
\hline
\end{tabular}

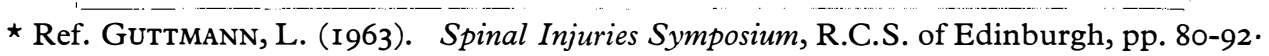


Causes of Acute Spinal Injuries

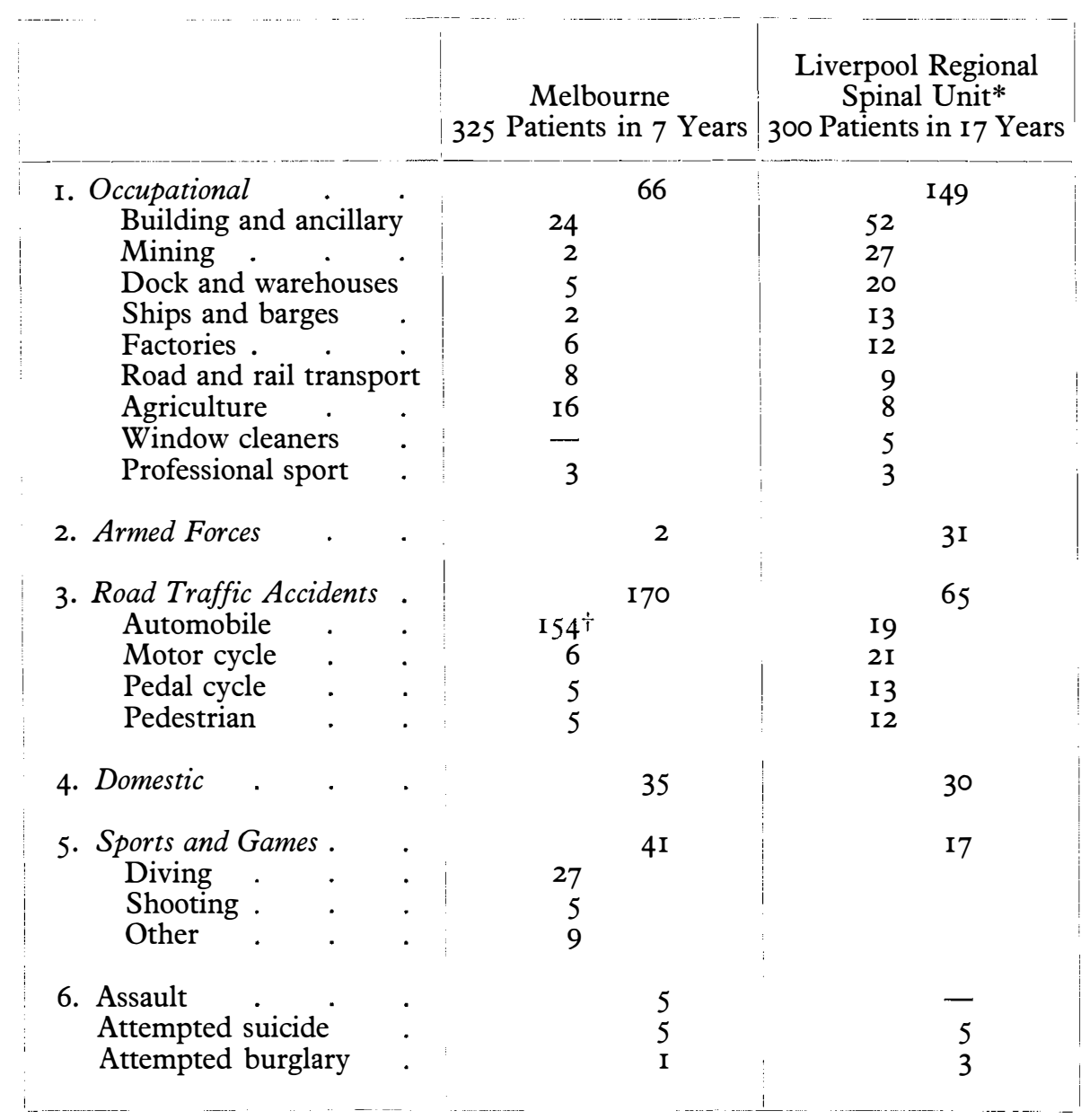

* Ref. Damanski, M. (1965). Int. F. Paraplegia, 2, i 7 I.

+ Of the 154 patients sustaining spinal cord injuries in automobile accidents, two were wearing seat belts-of the lap type. 
Relation Between Cord Damage and Vertebral Injury

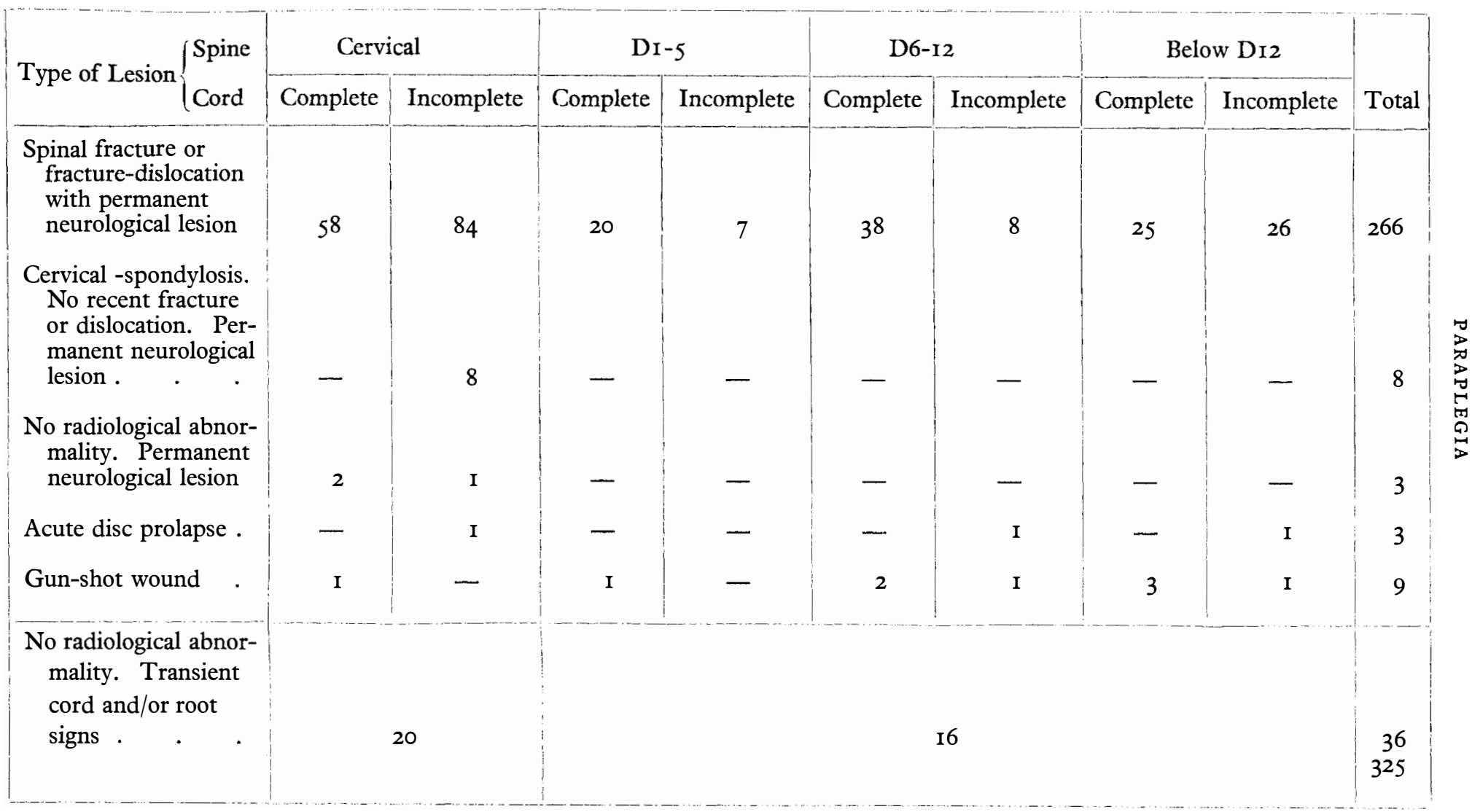


Relation Between Cord Damage and Vertebral Injury 226 Spinal Fractures or Fracture-Dislocations with Permanent Neurological Lesion

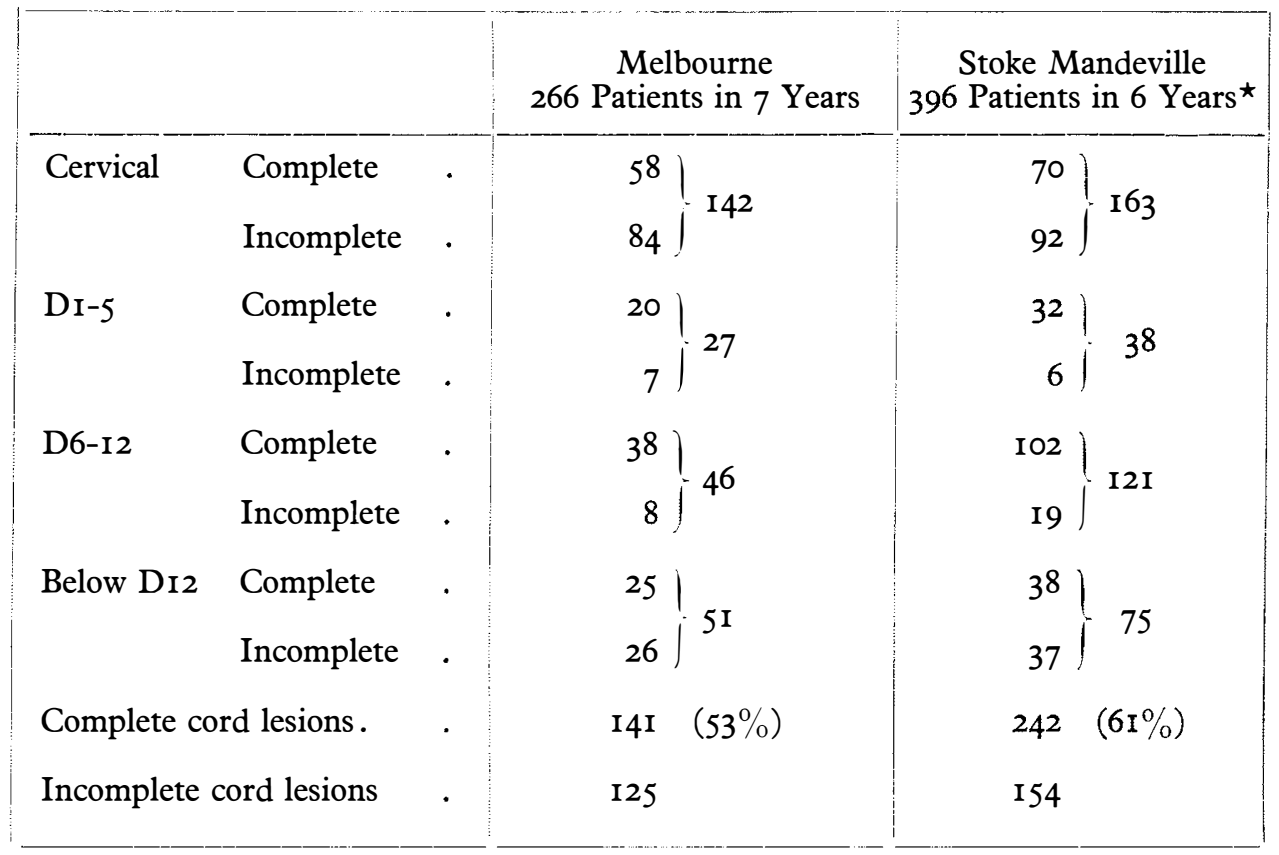

^ Ref. Guttmann, L. (1963). Spinal Injuries Symposium, R.C.S. of Edinburgh, pp. 80-92. 
Death Rate in 325 Cases of Spinal Cord Trauma

I. Acute Deaths (i.e. deaths within 60 days of accident)

Cause related to injury . . . . 20

Cause unrelated to injury . . . . .

2. Chronic Deaths (i.e. deaths more than 60 days after accident) . $\quad$. 24

Causes related to injury . . . . 20

Causes unrelated to injury . $\quad$. $\quad$. $\quad$. 4

All deaths . $\quad . \quad$. $\quad . \quad$. $\quad . \quad 54 \quad(16 \cdot 7 \%)$

'Related' deaths . $\quad . \quad$. $\quad . \quad$. $\quad .40 \quad(12 \cdot 0 \%)$

'Unrelated' deaths . . . . . $\quad$. $14 \quad(4.7 \%)$

Acute Deaths

I. Causes related to the Spinal Cord Injury . . . 20

Acute respiratory deaths . . . . . I4

Pulmonary embolus $\quad$. $\quad . \quad$. $\quad$. $\quad$. 2

Acute renal failure $\quad . \quad$. $\quad . \quad$. $\quad 2$

Acute staphylococcal septicaemia . . . . I

Cerebral abscess . . . . . . . . I

2. Causes unrelated to the Spinal Cord Injury . . . Io

(a) Death due to associated injuries $\quad$. 7

(i) Multiple injuries . . . 4

(ii) Head injuries $\quad . \quad$. 2

(iii) G.S.W. abdomen . . . . I

(b) Cardio-vascular disease . . . . 3

(i) Myocardial infarction . . 2

(ii) Congestive heart failure . . I

In 325 cases of acute spinal cord trauma, the 'crude' acute death rate was $9 \cdot 2$ per cent and the 'corrected' acute death rate was 6.I per cent. 


\section{Acute Respiratory Deaths in High Cervical Lesions}

\begin{tabular}{|c|c|c|c|c|c|c|}
\hline \multicolumn{5}{|c|}{ Lesion Level } & \multirow{2}{*}{ Cases } & \multirow{2}{*}{$\begin{array}{l}\text { Acute } \\
\text { Respiratory } \\
\text { Deaths }\end{array}$} \\
\hline Spine & Cord & & & & & \\
\hline \multirow[t]{2}{*}{$\mathrm{CI}-2$} & Complete & • & & • & I & I \\
\hline & Incomplete & . & & . & 5 & o \\
\hline \multirow[t]{2}{*}{$\mathrm{C}_{2-3}$} & Complete & . & • & . & 0 & 0 \\
\hline & Incomplete & . & . & . & I & 0 \\
\hline \multirow{2}{*}{$\mathrm{C}_{3}-4$} & Complete & . & . & . & 2 & I \\
\hline & Incomplete & . & & . & IO & I \\
\hline \multirow[t]{2}{*}{$\mathrm{C} 4-5$} & Complete & • & & . & I I & 2 \\
\hline & Incomplete & . & & . & IO & 0 \\
\hline
\end{tabular}

'High Cervical transections above C5-6 are usually fatal in a matter of hours or days; even in cases of incomplete transection at this level respiration is generally insufficient due to their depressed activity from spinal shock. Most of these patients soon develop a fatal pneumonia if they survive the initial injury.'-Austin, G. M. (196I). The Spinal Cord p. 17. Springfield: Thomas. 


\section{Domestic and Occupational Resettlement}

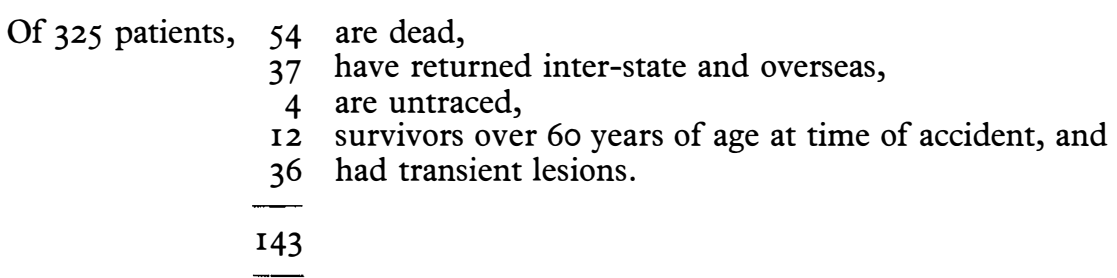

Thus 182 patients remain for analysis-all with a permanent neurological deficit.

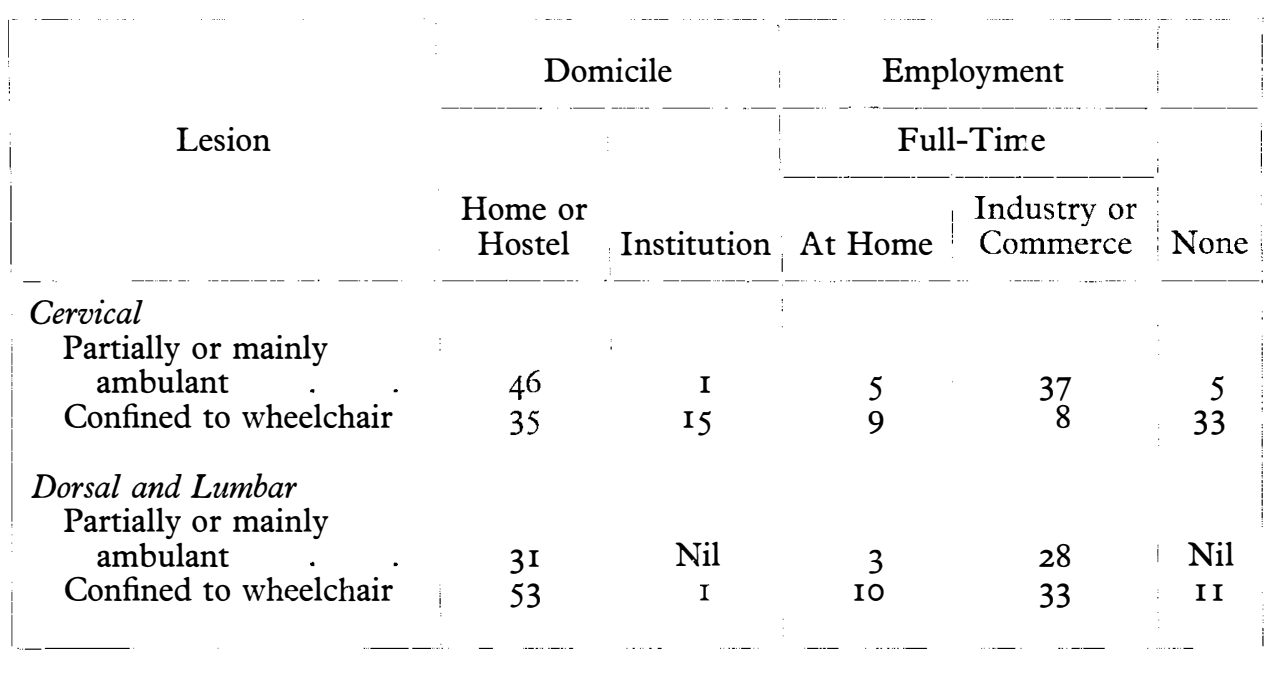

